\title{
Об изменениях в лексике русской лирической поэзии
}

\author{
МИХАЙ ПЕТЕР \\ ELTE BTK Orosz Nyelvi és Irodalmi Tanszék, H-1088 Budapest, Múzeum krt. 4/D. \\ E-mail: petermihaly28@gmail.com
}

(Received: 2 September 2019; accepted: 17 November 2019)

1. Выражение «язык поэзии» употребляется обычно в двояком смысле: с одной стороны, как специфичная коммуникативная система поэзии, по аналогии с выражениями «язык живописи», «язык танца» и др. (хотя направленность аналогии обратная); с другой стороны, как определенный язык, на котором написана совокупность поэтических произведений (см. ПЕтЕР 1977 и ПЕТЕР 1978). Так как второе определение нуждается в существенном уточнении, предпочитаю пользоваться выражением «поэтическая речь». О поэтическом языке как более или менее автономной коммуникативной системе можно говорить в отдельных случаях, например, в связи с санскритом, авестийским языком или древнескандинавской Эддой, а в известном смысле и относительно древнегреческой литературы, в которой лирические, эпические и драматические произведения зазвучали на различных диалектах.

2. Поэтическую речь не следует считать одним из функциональных стилей языка. Функциональные стили - это варианты общелитературного языка, которые выполняют свои задачи, подчиняясь определенным селекционным правилам (ограничениям) в употреблении синонимических средств языка. Поэтическая же речь служит целям эстетически действенного общения, она в большей или меньшей степени отмежевывается от повседневного языка, хотя полностью никогда не отрывается от него. В поэтической речи индивидуальная сфера употребления языка играет несравненно бо́льшую роль, чем в языковых стилях; отдельные тексты в языковых стилях являются обычно только образцами коллективного, общественного употребления. (Определенным языковым чертам достается несколько бо́льшая роль в переходных «полухудожественных» текстах, например, в публицистике.) Поэтическая же речь характеризуется исторически изменчивым, сложным взаимовлиянием индивидуального и коллективного узуса. Одним из главных факторов эстетически действенной поэтической речи является ее новаторство, которое отчасти сохраняет, отчасти же превышает литературную традицию. Стили языка - это исторически сложившиеся и общественно определенные, «инвентаризуемые» и классифицируемые варианты обыкновенного языкового употребления, соотносимые с разными широко осмысленными общественными контекстами. Контексты же, релевантные для отдельных поэтических текстов, принципиально единичны и неограниченно разнообразны. 
Языковые стили, будучи замкнутыми системами, основаны на обязательном или привилегированном употреблении одних и на исключении других языковых средств. Современная же поэтическая речь может питаться изо всех существующих или когда-то существовавших вариантов языка. Языковые стили взаимно «переводимы» друг на друга, и в ходе «перевода» изменяется, главным образом, коннотация текста. Поэтический же текст, ввиду своей единичности и семантической сложности, принципиально не переводим без существенного семантического и эстетического убытка ни на повседневный язык, ни на чужую поэтическую речь (см. ПЕТЕР 1978: 497).

3. Различение классицизма и романтики важно и при изучении поэтической речи. В то же время под этими терминами следует понимать не только два художественных направления, господствовавшие в определенные исторические эпохи, но - вслед за В. М. Жирмунским - и два вневременных типа поэтического творчества: «Классический поэт имеет перед собой задание объективное: создать прекрасное произведение искусства, законченное и совершенное, самодовлеющий мир, подчиненный своим особым законам... Момент субъективный при этом в рассмотрение не входит... Напротив, поэтромантик в своем произведении стремится прежде всего рассказать нам о себе, ,раскрыть свою душу“... Романтическое произведение легко становится дневником переживаний, интимных импрессий, ,,человеческим документом“” (ЖиРмунский 1977: 134-135).

Ниже попытаюсь представить на некоторых произвольно выбранных примерах общую тенденцию изменения в лексике русской поэтической речи за истекшие двести лет, учитывая при этом (хотя и с некоторой оговоркой) предупреждение замечательного филолога Б. А. Ларина: «Поэзии Данте, Хафиза или Пушкина для нас не воскресить в ее первой действенности. „Вечно“ может существовать только призрак поэзии, а полным, живым голосом она звучит только раз. Вот почему, если хотим исследовать семантический эффект лирики в его полноте, мы должны обратиться к поэтам-современникам» (ЛАРИН 1974: 78).

4. Белинский считал Ломоносова «Петром Великим русской литературы» и вел начало новой русской литературы от его «Оды на взятие Хотина» 1739 г. (цит. БЛАГой 1972: 57). Вот первые две строфы этой оды:

Восторг внезапный ум пленил, Ведет на верьх горы высокой, Где ветр в лесах шуметь забыл; В долине тишина глубокой.

Внимая нечто, ключ молчит, Который завсегда журчит И с шумом вниз с холмов стремится. Лавровы вьются там венцы, Там слух спешит во все концы; Далече дым в полях курится.
Не Пинд ли под ногами зрю? Я слышу чистых сестр музыку! Пермесским жаром я горю, Теку поспешно к оных лику. Врачебной дали мне воды: Испей и все забудь труды; Умой росой Кастальской очи, Чрез степь и горы взор простри И дух свой к тем странам впери, Где всходит день по темной ночи. 
Текст оды выдержан в высоком стиле, характерном для данного жанра. $\mathrm{O}$ «высокости» отдельных лексических элементов можно судить как бы в обратном порядке на основании стилистических отметок в Словаре Ушакова (1935 г.), в котором слова ветр, зрю, испей и отдельные элементы в словосочетаниях внимая нечто, сльшу чистых сестр музыку, Теку поспешно к оных лику отмечены как книжные, поэтические, риторические, устарелые. Характерными аксессуарами классицизма являются и упоминания Пиндара (классика торжественно-хоровой лирики), мифологической реки Пермесс (символа поэзии) и Кастильского источника (символа вдохновения).

5. Поэтическое творчество Г. Державина характеризуется разложением строгой системы классицизма как в жанровом, так и в стилевом отношении. По мнению известного историка литературы Г. Макогоненко, объектом изображения у Державина становился реальный мир; его индивидуальный стиль «означал становление реализма в лирике» (МАКогоненко 1969: 409, 414). Более осмотрительно высказался Белинский, считавший, что «Поэзия Державина есть безвременно явившаяся [...] поэзия пушкинская, а поэзия пушкинская есть вовремя явившаяся [...] поэзия державинская» (цит. БлАГой 1957: 74). По меткому замечанию Благова, ода «Фелица» явилась первым русским стихотворением XVIII в., «построенным на непрерывной игре светотенью» (БЛАГой 1957: 28). «В нем одические похвалы Екатерине II сочетаются с сатирическими обличениями наиболее влиятельных лиц из ее ближайшего окружения» (БлАГой 1957: 28). Вот первые шесть строф оды:

Богоподобная царевна

Киргиз-Кайсацкия орды!

Которой мудрость несравненна

Открыла верные следы

Царевичу младому Хлору

Взойти на ту высоку гору,

Где роза без шипов растет,

Где добродетель обитает!

Она мой дух и ум пленяет;

Подай найти ее совет.

Подай, Фелица, наставленье,

Как пышно и правдиво жить,

Как укрощать страстей волненье

И счастливым на свете быть.

Меня твой голос возбуждает,

Меня твой сын препровождает;

Но им последовать я слаб.

Мятясь житейской суетою,

Сегодня властвую собою,

А завтра прихотям я раб.

Мурзам твоим не подражая,

Почасту ходишь ты пешком,
Не слишком любишь маскарады, А в клоб не ступишь и ногой;

Храня обычаи, обряды,

Не донкишотствуешь собой;

Коня парнасска не седлаешь,

К духам в собранье не въезжаешь,

Не ходишь с трона на Восток;

Но кротости ходя стезою,

Благотворящею душою,

Полезных дней проводишь ток.

А я, проспавши до полудни,

Курю табак и кофе пью;

Преобращая в праздник будни,

Кружу в химерах мысль мою;

То плен от персов похищаю,

То стрелы к туркам обращаю;

То, возмечтав, что я султан,

Вселенну устрашаю взглядом;

То вдруг, прельщаяся нарядом,

Скачу к портному по кафтан.

Или в пиру я пребогатом,

Где праздник для меня дают, 
И пища самая простая

Бывает за твоим столом;

Не дорожа твоим покоем,

Читаешь, пишешь пред налоем

И всем из твоего пера

Блаженство смертным проливаешь;

Подобно в карты не играешь,

Как я, от утра до утра.
Где блещет стол сребром и златом,

Где тысячи различных блюд, -

Там славный окорок вестфальской,

Там звенья рыбы астраханской,

Там плов и пироги стоят, -

Шампанским вафли запиваю

И все на свете забываю

Средь вин, сластей и аромат.

Произведение по существу сочетает в себе оду и сатиру, лирическое и ироническое начало, патетику и бытопись; как сложное жанровое образование, оно открывает новый путь в литературе, «который в широкой исторической перспективе... приводит нас к „пестрым главам“ „Евгения Онегина“ и к весьма сложному жанру „Медного всадника“» (БлАгой 1957: 29). Из реалистических черт стиля Державина особое внимание заслуживает его блестящий колоризм, богатство красок, которым отличаются его картины природы и натюрморты; в них проступают ростки импрессионизма. В стилевом отношении лексика «Фелицы» представляет собой своеобразную смесь славянизмов (младому Хлору, блещет стол сребром и златом) и книжно-устарелых слов (обитает, препровождает, мятясь житейской суетою, благотворящею душою, кротости ходя стезою, полезных дней проводишь ток, кружу в химерах мысль мою); ироническое донкишотствуешь (с французским произношением) и коня парнасска не седлаешь чередуются с повседневно-бытовыми кофе пью, славный окорок вестфальской, шампанским вафли запиваю. В синтаксисе встречаются краткие формы прилагательных в функции определения (мудрость несравненна, взойти на ту высоку гору, коня парнасска). Экспрессивную функцию выполняют в тексте антитезы (Сегодня властвую собою, А завтра прихотям я раб; То, возмечтав, что я султан, Вселенну устрамаю взглядом; То вдруг, прельщаяся нарядом, Скачу к портному по кафтан).

6. Белинский считал Жуковского «литературным Коломбом Руси, открывшим ей Америку романтизма в поэзии» (цит. КовАРский 1958: 21); он же определил романтизм так: «В теснейшем и существеннейшем своем значении романтизм есть не что иное, как внутренний мир души человека, сокровенная жизнь его сердца» (КовАРский 1958: 22). И дальше: «В литературе Жуковского душевная жизнь человека предстает... как нечто сложное, противоречивое, как поток эмоций и мыслей, друг с другом связанных, друг в друга переходящих, взаимодополняющих, взаимообусловленных» (КовАРский 1958: 29).

Привожу начало стихотворения Жуковского «Невыразимое (Отрывок)»:

Что наш язык земной пред дивною природой?

С какой небрежною и легкою свободой

Она рассыпала повсюду красоту

И разновидное с единством согласила!

Но где, какая кисть ее изобразила? 
Едва-едва одну ее черту

С усилием поймать удастся вдохновенью...

Но льзя ли в мертвое живое передать?

Кто мог создание в словах пересоздать?

Невыразимое подвластно ль выраженью?..

Святые таинства, лишь сердце знает вас.

Не часто ли в величественный час

Вечернего земли преображенья,

Когда душа смятенная полна

Пророчеством великого виденья

И в беспредельное унесена, -

Спирается в груди болезненное чувство,

Хотим прекрасное в полете удержать,

Ненареченному хотим названье дать -

И обессиленно безмолвствует искусство?

Выдающийся филолог Г. А. Гуковский считал это стихотворение Жуковского «как бы декларацией его художественного кредо, его литературным манифестом» (Гуковский 1965: 46). Основную мысль Жуковского Гуковский усматривал в том, что «искусство призвано передавать лишь то невыразимое душевное волнение, те зыбкие оттенки настроений, [...] для которых внешняя природа является лишь условным возбудителем, поводом. [...] поэзия должна перестать быть точным называнием понятий, ибо нельзя точно назвать сложное, смутное, противоречивое состояние души... слово теряет свою общезначимую терминологичность, свойственную ему в классицизме. Слово должно звучать как музыка, и в нем должны выступать вперед его эмоциональные обертоны, оттесняя его предметный, объективный смысл... Слово должно преодолеть свою рациональную функцию, чтобы вызвать ответное душевное движение» (Гуковский 1965: 47-48). «Объективное утоплено в словах эмоций; величественно переживание вечера, а не сам вечер; преображение - это слово не внешней природы, а молитвенного экстаза» (Гуковский 1965: 49).

Как слит с прохладою растений фимиам!

Как сладко в тишине у брега струй плесканье!

Как тихо веянье зефира по водам

И гибкой ивы трепетанье!

Для Жуковского в этой строфе его стихотворения «Вечер» прохлада обозначает не «объективный» воздух, а субъективное переживание воздуха «это состояние духа, [...] легкое, свободное переживание жизни природы» в жизни поэта; фимиам - это не запах, а «молитвенное настроение, умиление и вдохновение, возносящееся к небу»; трепетанье - «это нежное, музыкальное слово, говорящее о стыдливости, о тончайшей вибрации - чего? души 
поэта, - хотя в то же время и ивы» (Гуковский 1965: 61). Гуковский с тонким чутьем открывает поэтическое новаторство Жуковского, расширявшего семантику слова, так сказать, не вширь, а вглубь. Однако его тщательный анализ нуждается в небольшом уточнении: в поэтической практике Жуковского объективное («простое», понятийное) значение слова не выветривается полностью: оно сохранено в диалектическом единстве с выдвинутыми на первый план субъективными значениями. Как известно, полная утрата объективного значения слова привела бы к «зауми», а «заумь» не есть ни язык, ни поэзия.

7. С творчеством Н. А. Некрасова связано значительное обновление поэтической речи. Стиль его поэзии необычайно изменчив и гибок, его разнообразие определяется широтой тематики его произведений. В его поэзии часто звучит голос оратора и трибуна, что придает многим его стихам характер торжественной риторики (см. ЭйхенБАУм 1969: 57). Избегая высокопарную романтическую лексику, Некрасов с глубоким сочувствием изображает безвыходно трудную жизнь крепостных крестьян, простого народа; он достоверно воспроизводит народную речь (без излишних диалектизмов и арготизмов) и вместе с тем передает скупыми выразительными средствами характерную речь различных общественных слоев: чиновников, церковников, купцов и др.

Стоит сопоставить изображение Петербурга у Пушкина и у Некрасова. У Пушкина противоречивое отношение к городу. С одной стороны:

Город пышный, город бедный, Дух неволи, стройный вид.

Свод небес зелено-бледный,

Скука, холод и гранит...

Здесь город чопорный, унылый,

Здесь речи - лед, сердца - гранит;

С другой стороны, восторженный гимн «Петра творенью» во Вступлении к поэме «Медный всадник»:

Люблю зимы твоей жестокой Недвижный воздух и мороз, Бег санок вдоль Невы широкой, Девичьи лица ярче роз, И блеск, и шум, и говор балов...
Люблю воинственную живость Потешных Марсовых полей, Пехотных ратей и коней Однообразную красивость...

\section{У Некрасова:}

Начинается всюду работа;

Возвестили пожар с каланчи; На позорную площадь кого-то Провезли - там уж ждут палачи.
Торгаши просыпаются дружно И спешат за прилавки засесть: Целый день им обмеривать нужно, Чтобы вечером сытно поесть. 
Проститутка домой на рассвете Поспешает, покинув постель; Офицеры в наемной карете Скачут за город: будет дуэль.
Чу! из крепости грянули пушки! Наводненье столице грозит... Кто-то умер: на красной подушке Первой степени Анна лежит.

Дворник вора колотит - попался!

Гонят стадо гусей на убой;

Где-то в верхнем этаже раздался

Выстрел - кто-то кончил с собой...

В стихотворении «Утро» показана картина оживленного будничного утра большого города: проститутка, идущая домой, «покинув постель»; офицеры, скачущие за город на место дуэли; торгаши, спешащие к своим прилавкам; дворник, бьющий попавшегося вора; зловещие сигналы о пожаре и о грозящем наводнении; слышится выстрел покончившего с собой самоубийцы... Лаконично перечисленные события следуют друг за другом как кинокадры и создают реалистически мрачный вид утреннего Петербурга. Ни одно взволнованное слово не нарушает (кажущийся) деловой тон текста.

В протокольно-деловитом стиле, с точным указанием места и времени события написано следующее восьмистишие поэта:

Вчерашний день, часу в шестом,

Зашел я на Сенную,

Там били женщину кнутом,

Крестьянку молодую.

Ни звука из ее груди,

Лишь бич свистал, играя...

И Музе я сказал: «Гляди!

Сестра твоя родная!»

Только в двух последних строчках проявляется в эмблематически сжатом виде основной пафос всей некрасовской поэзии...

\section{8.}

Как велит простая учтивость,

Подошел ко мне, улыбнулся,

Полуласково, полулениво

Поцелуем руки коснулся -

И загадочных древних ликов

На меня поглядели очи...

Десять лет замираний и криков,

Все мои бессонные ночи

Я вложила в тихое слово

И сказала его - напрасно.

Отошел ты, и стало снова

На душе и пусто и ясно.

Это стихотворение, состоящее из двух шестистрочных строф, представляет собой блестящий образец столь характерного для поэзии Анны Ахматовой лаконизма. Оно является, собственно, маленькой новеллой, рассказывающей о краткой встрече - после десятилетнего перерыва - с любимым человеком. Все, что произошло во время этой встречи, сконцентрировано между двумя нейтральными глаголами подошел и отошел. Вслед за осторожно сдержанным приветствием со стороны мужчины (полуласково, полулениво) 
у героини вспыхивает воспоминание о былых переживаниях любовного романа: ее возрожденное чувство выражается в высоких, «поэтических» словах загадочных древних ликов... очи, а также в словах о ее последующих страданиях (годы замираний и криков... бессонные ночи). Все эти воспоминания она теперь вложила в тихое слово, но - напрасно. Он не понял или не захотел понимать и - отошел. А на душе героини стало снова $и$ пусто и ясно. В этих казалось бы простых и сдержанных, а на самом деле богатых и в смысловом, и в эмоциональном отношении - двух наречиях выражена вся душевная драма героини.

\section{9.}

Ночь, улица, фонарь, аптека, Бессмысленный и тусклый свет. Живи еще хоть четверть века Все будет так. Исхода нет.
Умрешь - начнешь опять сначала, И повторится все, как встарь: Ночь, ледяная рябь канала, Аптека, улица, фонарь.

В стихотворении Александра Блока изображена вполне обыденная сцена. Поэт, вероятно страдающий бессонницей, видит из окна своей комнаты наскучившую ему обычную картину неподвижной ночной улицы. Этот вид, будто обернувшись сложной метафорой, вызывает в нем чувство безвыходной неизменности его собственной судьбы, а также зловещей неподвижности времени вообще. (Стихотворение было написано осенью 1912 года...) Синтаксис текста подчеркнуто простой: краткие, бессоюзно связанные фразы, номинативные и обобщенно-личные предложения. Лексика полностью прозаична. Экспрессивно отрицательна коннотация эпитетов бессмысленный, тусклый, ледяная. Эпитет бессмысленный намекает на омонимическое значение существительного свет ('освещение' и 'земной шар, мир'). Секрет стихотворения в его композиции: текст построен в виде эпанода (от греч. ерáno$d o s$ 'возвращение') - фигуры, в которой слова или выражения повторяются после некоторого отступления в обратном порядке. В самой этой фигуре наглядно выражен смысл стихотворения: вечный круговорот явлений, воспринимаемый нами как трагическая неизменяемость.

10. Евгений Винокуров был одним из ярких представителей талантливого поколения поэтов, которое, пройдя суровое время войны, обрело свой поэтический голос в шестидесятые годы.

Когда-нибудь однажды в гастрономе Я выбью сыра двести грамм и, руку Протягивая с чеком продавщице, Увижу вдруг, что рядом - это ты.

Я руку с чеком опущу. В сторонку Мы к кассе тут же отойдем и будем О том, о сем, о пятом, о десятом Средь толчеи негромко говорить.
И ты заметишь, что давно не брита Седая на щеках моих щетина, Что пуговица кое-как пришита И обмахрились рукава пальто.

Я ж про себя отмечу, что запали Глаза твои, что неказиста шляпка С тряпичной маргариткой и что зонтик Давно пора отдать бы починить. 
Простимся. И когда в толпе исчезнешь, Мне вслед тебе захочется вдруг крикнуть, Что разошлись, ей-богу же, напрасно С тобой мы тридцать лет тому назад.

В стихотворении Винокурова рассказана в новеллистически сжатом виде предполагаемая случайная встреча былых любовников через тридцать лет после их расставания. Виртуальная встреча описана в «микрореалистическом» стиле: равнодушный разговор о том, о сем, сопровождаемый невольным взаимным наблюдением за следами, которые минувшие годы оставили на внешности героев. Стихотворение написано безрифменным пятистопным ямбом; тройное созвучие в третьей строфе (брита... щетина.. пришита) подчеркивает первое впечатление героини о невыгодном изменении внешности ее бывшего возлюбленного. И только в конце встречи вспыхнет у него осознание того, что напрасно было расставание тридцать лет тому назад...

11. Приведенные отрывки стихотворных текстов указывают на некоторую тенденцию стилевого снижения лексики в русской поэтической речи. Возникает вопрос: не свидетельствует ли эта тенденция о какой-то «депоэтизации» лирики? На мой взгляд: нет. Основным материалом стихотворения как художественного произведения является языковой текст, состоящий из слов, их синтаксических связей и звучащих элементов (метр, ритм, интонация, рифма, звукопись). Все эти факторы могут участвовать в создании поэтических образов. В то же время более глубокий смысл («содержание») стихотворения определяется, как правило, и другими факторами: близкими и более дальними контекстами, связанными с автором, адресатом, темой произведения, включая и некоторые элементы литературной традиции. При этом значение самого текста является часто многослойным: рядом с «простым», обыкновенным значением лексических элементов, поэтической коммуникации служат и их различные скрытые (имплицитные), синонимические, метафорические и др. связи; короче говоря: эстетически полноценное стихотворение представляет собой такой художественный комплекс («Gesamtkunstwerk»), отдельные (часто иерархически устроенные) факторы которого взаимно усиливают и взаимно дополняют друг друга. Таким образом, нарастающее включение обиходной лексики в поэтическую речь не следует огульно рассматривать как «депоэтизацию» русской лирики.

\section{Источники}

Ахматова 1976 = АхматовА А. Стихотворения и поэмы. (Библиотека поэта. Большая серия.) Ленинград: «Советский писатель», 1976.

Блок 1958 = Блок А. Стихотворения. (Библиотека поэта. Большая серия.) Ленинград: «Советский писатель», 1958.

Винокуров 1964 = Винокуров Е. Музыка. Новые стихи. Москва: «Советский писатель», 1964. 
Жуковский 1958 = Жуковский В. А. Стихотворения и поэмы. (Библиотека поэта. Малая серия.) Ленинград: «Советский писатель», 1958.

КОКОРеВ 1952 = КОКОРЕВ А. В. (сост.) Хрестоматия по русской литературе ХVIII века. Москва: «Учпедгиз», 1952.

НЕКРАСов 1956 = НекРАСов Н. А. Стихотворения. Т. 1. (Библиотека поэта. Малая серия.) Ленинград: «Советский писатель», 1956.

\section{Литература}

БЛАГой 1957 = БЛАГой Д. А. Гаврила Романович Державин. В кн.: ДЕРжАВин Г. Р. Стихотворения. Ленинград: «Советский писатель», 1957. 5-74.

БЛАГОЙ 1972 = БЛАГОй Д. От Кантемира до наших дней. Т. 1. Москва: «Художественная литература», 1972.

Гуковский 1965 = Гуковский Г. А. Пушкин и русские романтики. Москва: «Художественная литература», 1965.

ЖиРмунский 1977 = ЖиРмунский В. М. О поэзии классической и романтической. В кн.: Жирмунский В. М. Теория литературы, поэтика, стилистика. Ленинград: «Наука», 1977. 134-137.

КовАРСКИЙ 1958 = КовАРСКИй Н. Поэзия Жуковского. В кн.: Жуковский В. А. Cmuхотворения и поэмы. Ленинград: «Советский писатель», 1958. 3-34.

ЛАРИН 1974 = ЛАРИн Б. А. Эстетика слова и язык писателей. Ленинград: «Художественная литература», 1974.

МАКОГОНЕНКО 1969 = МАКОГОНЕнко Г. От Фонвизина до Пуикина. Москва: «Художественная литература», 1969.

ПЕTEP 1977 = ПЕTЕР М. К вопросам семантики поэтического языка. В кН.: РЕ́теR М. (ed.): The Structure and Semantics of the Literary Text. Budapest: Akadémiai Kiadó, 1977. 57-74.

ПЕТЕР 1978 = ПЕТЕР М. Существует ли «Поэтический язык»? Zeitschrift für Slawistik 23 (1978): 494-500.

ЭЙХЕНБАУМ 1969 = ЭЙХЕНБАУМ Б. М. О поэзии. Ленинград: «Советский писатель», 1969.

MIHÁLy PÉTER

Department of Russian Language and Literature, Eötvös Loránd University (Budapest)

\section{On Changes in the Vocabulary of Russian Lyric Poetry}

The paper intends to present the general tendency of lexical change in Russian lyrical poetry during the last two hundred years on some arbitrarily selected examples. The odes of Lomonosov were accomplished in the lofty style based on Slavonic, rhetorical, and other "poetical" devices. In Derzhavin's ode Felica, enthusiastic and ironical elements, pathos and everyday talk are combined. In Zhukovski's romantic poetry the objective sense of words is overshadowed by their emotive overtones. In avoiding the grandiloquent romantic lexis, Nekrasov describes the hopeless hard life of Russian peasantry with deep sympathy, and reliably reproduces the popular speech. In the cited poem of Akhmatova, the psychic drama of the heroine is expressed by a peculiar connection of words belonging to different 
stylistic layers. The entirely prosaic lexis and syntax of Blok's short poem suggests the poet's feeling about the hopeless immobility of life in a condensed metaphoric shape. Vinokurov's poem relates an imagined accidental meeting of former lovers after thirty years of their separating in an entirely colloquial style. Since a poem of genuine aesthetic value appears as a complex artistic work, its components mutually strengthen, supplement, or compensate each other. Thus, the increase of colloquial elements in the poetic vocabulary does not necessarily indicate a process of "depoetization".

Keywords: styles of language and poetic speech, approach of the poetic vocabulary to colloquial language in Russian lyric poetry, extracts from the poetry of Lomonosov, Derzhavin, Zhukovsky, Nekrasov, Blok, Akhmatova, Vinokurov

Open Access. This is an open-access article distributed under the terms of the Creative Commons Attribution 4.0 International License (https://creativecommons.org/licenses/ by/4.0), which permits unrestricted use, distribution, and reproduction in any medium, provided the original author and source are credited, a link to the CC License is provided, and changes - if any - are indicated. (SID_1) 